\title{
Comparison of tiotropium once daily, formoterol twice daily and both combined once daily in patients with COPD
}

\author{
J.A. van Noord*, J-L. Aumann\#, E. Janssens`, J.J. Smeets*, J. Verhaert", \\ B. Disse ${ }^{+}$, A. Mueller ${ }^{+}$and P.J.G. Cornelissen ${ }^{+}$
}

ABSTRACT: This study compared the bronchodilator effects of tiotropium, formoterol and both combined in chronic obstructive pulmonary disease (COPD).

A total of 71 COPD patients (mean forced expiratory volume in one second (FEV 1 ) $37 \%$ predicted) participated in a randomised, double-blind, three-way, crossover study and received tiotropium $18 \mu \mathrm{g}$ q.d., formoterol $12 \mu \mathrm{g}$ b.i.d. or both combined q.d. for three 6-week periods. The end-points were 24-h spirometry (FEV 1 , forced vital capacity (FVC)) at the end of each treatment, rescue salbutamol and safety.

Compared with baseline (FEV 1 prior to the first dose in the first period), tiotropium produced a significantly greater improvement in average daytime FEV 1 (0-12 h) than formoterol (127 versus $86 \mathrm{~mL}$ ), while average night-time FEV $1(12-24 \mathrm{~h})$ was not different (tiotropium $43 \mathrm{~mL}$, formoterol $38 \mathrm{~mL}$ ). The most pronounced effects were provided by combination therapy (daytime $234 \mathrm{~mL}$, night-time $86 \mathrm{~mL}$ ); both differed significantly from single-agent therapies. Changes in FVC mirrored the FEV 1 results. Compared with both single agents, daytime salbutamol use was

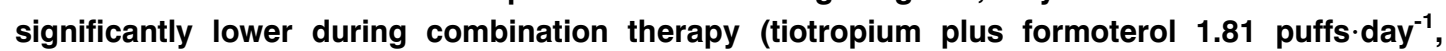
tiotropium 2.41 puffs $\cdot$ day $^{-1}$, formoterol 2.37 puffs $\cdot$ day $^{-1}$ ). All treatments were well tolerated.

In conclusion, in chronic obstructive pulmonary disease patients, tiotropium q.d. achieved a greater improvement in daytime and comparable improvement in night-time lung function compared with formoterol b.i.d. A combination of both drugs q.d. was most effective and provided an additive effect throughout the 24-h dosing interval.

KEYWORDS: Chronic obstructive pulmonary disease, combination therapy, formoterol, inhaled long-acting anticholinergic, inhaled long-acting $\beta_{2}$-agonist, tiotropium

hronic obstructive pulmonary disease (COPD) is a progressive disease in patients experiencing increasing symptoms of airflow obstruction with limitations in their daytime physical activity. As the disease progresses, disability can become extreme, with limitations on even modest physical exertion disrupting daily life. Inhaled bronchodilator therapy is central in the treatment of COPD. When symptoms persist and are not adequately controlled with short-acting bronchodilators, recent guidelines recommend regular treatment with mono- or combination therapy of longacting bronchodilators $[1,2]$. In this respect, it is noted that, at present, no data exist on combination maintenance therapy with long-acting bronchodilators.

For editorial comments see page 190.
The currently available long-acting $\beta_{2}$-agonists (LABAs) salmeterol or formoterol provide significant increases in lung function for $\sim 12 \mathrm{~h}$ and relief of symptoms [3-5]. Recently, the new long-acting anticholinergic tiotropium has become available to clinical practice for the treatment of COPD $[6,7]$. In contrast to LABAs, which have a twice-daily dose regimen, oncedaily tiotropium maintains bronchodilation over $24 \mathrm{~h}$. The clinical benefit of this once-daily anticholinergic agent has been established in comparative 1-yr clinical studies versus placebo [8] and ipratropium bromide [9], and in two 6month studies versus salmeterol or placebo [10, 11]. Overall, tiotropium was found to be superior to these active agents in improving lung function.

Up to now, there have been no major clinical studies comparing tiotropium and formoterol in COPD, and a combination therapy of tiotropium
AFFILIATIONS

*Atrium medisch centrum, Heerlen, and

+Boehringer Ingelheim bv, Alkmaar, The Netherlands.

\#Virga Jesse Ziekenhuis, Hasselt, and

'Ziekenhuis Oost-Limburg, Lanaken, Belgium.

CORRESPONDENCE

J.A. van Noord

Dept of Respiratory Diseases

Atrium medisch centrum

Henri Dunantstraat 5

6419 PC Heerlen

The Netherlands

Fax: 31455767534

E-mail: j.a.vannoord@atriummc.nl

Received:

December 092004

Accepted after revision:

March 222005

SUPPORT STATEMENT

This study was supported by

Boehringer Ingelheim (Alkmaar, The Netherlands)
European Respiratory Journal Print ISSN 0903-1936 Online ISSN 1399-3003 
and an inhaled LABA has not been investigated in depth. As highlighted by TENNANT et al. [12], combination therapy of these long-acting agents could provide important benefits, since these drugs have complementary actions on the airways. In this respect, CAzzolA et al. [13] found a trend for additive effects of tiotropium and formoterol in COPD using a singledose study design. Previously, it has been shown that add-on therapy of formoterol in the morning to maintenance therapy of tiotropium significantly improved the spirometric variables of forced expiratory volume in one second (FEV1), forced vital capacity (FVC) and inspiratory capacity (IC) for $>12 \mathrm{~h}$ in COPD patients [14]. Add-on therapy with a second formoterol dose in the evening provided a further improvement in average FEV1, FVC and IC during the night-time hours, but not in the FVC and IC values the following morning (i.e. measured $12 \mathrm{~h}$ after the evening dose of formoterol). The use of rescue salbutamol during the night was very low and not different between treatments, indicating that the impact of the add-on evening formoterol dose was not reflected in the need for reliever medication and that the tiotropium component provided sufficient bronchodilation during the night-time. Once-daily combination therapy would be an attractive option, as it simplifies therapy and could enhance compliance.

Therefore, the purpose of the present study was to compare the bronchodilator effects of tiotropium q.d. with formoterol b.i.d. during a pharmacodynamic steady state, with serial spirometry over a 24-h observation period. In addition, the bronchodilator effects of a combination therapy of tiotropium and formoterol, administered q.d. in separate devices, was compared with those of single-agent therapies.

\section{METHODS \\ Patients}

Patients were male or female outpatients, aged $\geqslant 40 \mathrm{yrs}$, and current or ex-smokers with a $\geqslant 10$ pack-yr smoking history. All patients had a diagnosis of COPD [15] and were required to have a baseline FEV1 $\leqslant 60 \%$ predicted [16] and a FEV1/FVC $\leqslant 70 \%$. Specific exclusion criteria were a current or past diagnosis of asthma, atopy, allergic rhinitis or an elevated blood eosinophil count $\left(\geqslant 600 \mathrm{~mm}^{3}\right)$. Also, patients with any of the following were excluded: a clinically significant medical disorder other than COPD; recent history of myocardial infarction; heart failure or cardiac arrhythmia requiring drug therapy; oxygen therapy; known symptomatic prostatic hypertrophy; and narrow-angle glaucoma. Patients with a respiratory infection or COPD exacerbation in the 6 weeks prior to screening or during the run-in period were randomised 6 weeks following recovery from the event.

\section{Study design}

This was a three-centre, 20-week study consisting of a 2-week run-in period, followed by a randomised, double-blind, double-dummy, crossover design of three 6-week treatment periods. Following the screening visit, eligible patients entered a 2-week run-in period to ensure clinical stability (i.e. no exacerbations). Furthermore, this period was used to train the patients in the appropriate daily recording of as-needed use of salbutamol and peak expiratory flow rate (PEFR). Patients who successfully completed this phase were entered into the three 6-week periods, in which they received three treatment regimens in a randomised sequence (table 1 ). The evening dose of study drug was taken $\sim 12 \mathrm{~h}$ after the morning dose of study medication. The patients were allowed to continue the use of inhaled steroids and oral steroids up to the equivalent of $10 \mathrm{mg} \cdot$ day $^{-1}$ prednisone. All inhaled anticholinergic $(8 \mathrm{~h})$, short- $(8 \mathrm{~h})$ or long-acting inhaled $\beta_{2}$-agonist $(48 \mathrm{~h})$ medication use was discontinued at the end of the run-in period (tiotropium was not commercially available in the Netherlands and Belgium at the time of initiation). Theophylline preparations were not allowed for $\geqslant 1$ month prior to the screening visit. Open-label salbutamol was provided at the screening visit, and patients were instructed to use it as-needed for acute symptom relief. The study protocol was approved by the hospital medical ethics committees (Atrium medisch centrum, Heerlen, The Netherlands; Virga Jesse Ziekenhuis, Hasselt, and Ziekenhuis Oost-Limburg, Lanaken, Belgium), and written informed consent was obtained before any study procedure was undertaken.

\section{Measurements}

In addition to the qualifying spirometric tests (FEV1 and FVC) at the screening visit (visit 1), the bronchodilator responsiveness was assessed $1 \mathrm{~h}$ after inhalation of 4 puffs of salbutamol $100 \mu \mathrm{g}$ (in order to characterise the study population and not to be used as an inclusion criterion). Subsequently, one spirometric assessment was conducted following the 2-week run-in period (visit 2, i.e. randomisation visit), i.e. before inhalation of the first dose of randomised study medication, whereas serial measurements were conducted during a 24-h observation period at the end of each 6-week treatment period at the following time points: $10 \mathrm{~min}$ prior to the morning dose; 30

\section{TABLE 1 Treatment regimens of the three 6-week treatment periods}

\section{6-week treatment} period

Morning dose

\section{Treatment regimens}

Evening dose $\begin{array}{ll}1 & \text { Tiotropium } \# \text { powder capsule } 18 \mu \mathrm{g}+\text { formoterol-matched placebo" powder capsule } \\ \mathbf{2} & \text { Tiotropium-matched placebo\# }^{*} \text { powder capsule }+ \text { formoterol" powder capsule } 12 \mu \mathrm{g}\end{array}$

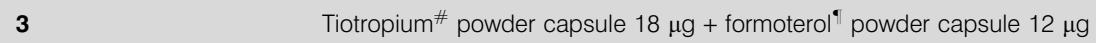

Formoterol-matched placebo" powder capsule Formoterol" powder capsule $12 \mu \mathrm{g}$ Formoterol-matched placebo" powder capsule

\#: tiotropium (Spiriva $\left.{ }^{\circledR}\right)$ and tiotropium-matched placebo powder capsule via HandiHaler (Boehringer Ingelheim International GmbH, Ingelheim/Rhein, Germany); formoterol (Foradil $\mathbb{R}$ ) and formoterol-matched placebo powder capsule via Aerolizer (Novartis Pharma AG, Basel, Switzerland). 
and $60 \mathrm{~min}$, and 2, 3, 4, 6, 8, 10 and $12 \mathrm{~h}$ after inhalation of the morning dose of study medication; and 30 and $60 \mathrm{~min}$, and 2, $7,10,11$ and $12 \mathrm{~h}$ after inhalation of the evening dose of study medication. Testing started between 08:00 and 10:00 $\mathrm{h}$ at the same time of the day, i.e. $\pm 30 \mathrm{~min}$ maximum difference between the start of the test at the randomisation visit and the tests on subsequent clinic visits. The measurements were performed with a spirometer meeting American Thoracic Society (ATS) criteria [17]. The highest values of FEV1 and FVC from three technically adequate measurements were retained. Vital signs were recorded at the same time intervals as pulmonary function testing. During the 2-week run-in period, as well as during the three 6-week treatment periods, patients recorded daily the as-needed use of salbutamol metered-dose inhaler (MDI) and twice-daily PEFR. PEFR was measured prior to study medication as the best of three manoeuvres, using the Personal Best Peak Flow Meter (Healthscan Products Inc., Cedar Grove, NJ, USA). Use of salbutamol MDI was recorded separately for daytime and night-time. At each scheduled visit to the clinic, details of clinical status, adverse events and withdrawals were recorded. Before entry and at the completion of study participation, patients underwent a medical examination, laboratory testing and a 12-lead ECG recording.

\section{Statistical analysis}

The planned sample size was 60 completed patients. Assuming a standard deviation of $140 \mathrm{~mL}$ for paired differences as observed in other trials $[18,19]$, this sample size provides a power of $90 \%$ to detect a true difference of $60 \mathrm{~mL}$ in average FEV1 over $24 \mathrm{~h}$ (type I error rate: 0.05 ), resulting in an overall power for the first four comparisons (combination versus single agents) of $\geqslant 80 \%$.

The primary efficacy end-points were the average FEV1 over the first $12 \mathrm{~h}(0-12 \mathrm{~h})$ and over the full 24-h observation period (0-24h) on the last day of each 6-week period of randomised treatment. The average FEV1 was calculated as the area under the curve from zero time to 12 or $24 \mathrm{~h}$ (or 12-24 h), respectively, using the trapezoidal rule divided by the corresponding duration (i.e. 12 or $24 \mathrm{~h}$ ) to give the result in litres. The pre-dose FEV1 value was assigned to zero time and defined as the measurement before administration of the last morning dose of study drug at the end of each 6-week treatment period. Secondary end-points were trough and peak FEV1, as well as FEV1 values at individual time points. Trough was defined as the value measured at the end of the 24-h observation period at the end of each 6-week treatment period, i.e. $\sim 24$ and $12 \mathrm{~h}$ after the last morning, respectively, evening dose of study medication. The peak FEV1 was the highest FEV1 reading observed within $3 \mathrm{~h}$ after inhalation of the morning study medication. Average, trough and peak responses were defined as the change from the baseline FEV1 value, which was the measurement obtained on visit 2 (randomisation visit) prior to the first morning dose of randomised study medication. Analogous definitions were used for FVC-based parameters. Patient diary-based end-points were twice-daily PEFRs (morning and evening) and as-needed salbutamol use (daytime and night-time). To eliminate possible carry-over effects, the data obtained in the first 3 weeks of each 6-week treatment period were discarded [20, 21]; the mean of observations obtained in the last 3 weeks of each treatment period were calculated and used to compare the treatment regimens. The run-in period was used for training purposes; diary data recorded in this period were not used for the analysis.

For all end-points, adjusted means for the three treatments were calculated using a fixed-effects ANOVA model with terms for centre, patients within centre, treatment and period, as specified in the study protocol. All patients with ontreatment data available were included in the analysis (safety: $n=74$; diary and spirometric end-points: $n=71$ and $n=69$, respectively). No period effect could be detected, whereas centre and patient were found significant (F-test $p<0.05)$ for the primary and most of the secondary end-points. Sensitivity analysis did not reveal a treatment by centre interaction. For the primary end-points, treatment means were compared in a pre-specified order to control type-I error rate (fixed sequence testing). For other end-points, no adjustments for multiple comparisons were utilised. In order to include the same patients at each time point in the spirometric summaries, missing values were estimated using other values recorded for the patient on that 24-h pulmonary function test day. Randomly missing trough values were estimated by the value obtained as a test day pre-dosing reading and vice versa. The linear interpolation between two adjacent measurements was used to estimate the middle missing spirometric measurements, and the last observation carried forward method was applied if no subsequent measurement was available. Values that were missing for reasons related to the patient's treatment response, e.g. shortness of breath and use of rescue medication, were estimated using the minimum observed spirometric measurement on a specific test day. For diary end-points, similar rules were applied.

\section{RESULTS}

A total of 74 patients were randomised to treatment and eight patients prematurely discontinued the study. One patient withdrew informed consent and seven patients discontinued due to adverse events. Three patients discontinued the study in the first 3 weeks of the first treatment period and, therefore, had no efficacy data that could be used for the comparison of treatment arms (fig. 1). The demographics and baseline characteristics of the 71 patients included in the efficacy analysis are presented in table 2.

\section{Lung function}

The mean \pm SE baseline FEV1 at the start of the treatment periods was $1.019 \pm 0.03 \mathrm{~L}$. After 6 weeks of treatment with tiotropium q.d., formoterol b.i.d. or tiotropium plus formoterol q.d., the pre-dose values were $1.127 \pm 0.01 \mathrm{~L}, 1.091 \pm 0.01 \mathrm{~L}$ or $1.134 \pm 0.01 \mathrm{~L}$, respectively, and the difference between the combination and formoterol was significant $(p<0.05)$.

The 24-h FEV1 profiles for the three treatments are presented in figure 2. Following inhalation of the morning dose of tiotropium or formoterol, the improvements in FEV1 were comparable between the two bronchodilators until $8 \mathrm{~h}$ after dosing. From 8 to $12 \mathrm{~h}$, post-dose tiotropium provided a significantly greater improvement in FEV1 compared with formoterol in the range of $0.064 \mathrm{~L}(\mathrm{p}<0.002)$ to $0.081 \mathrm{~L}$ $(p=0.0001)$. After inhalation of the second (evening) formoterol 


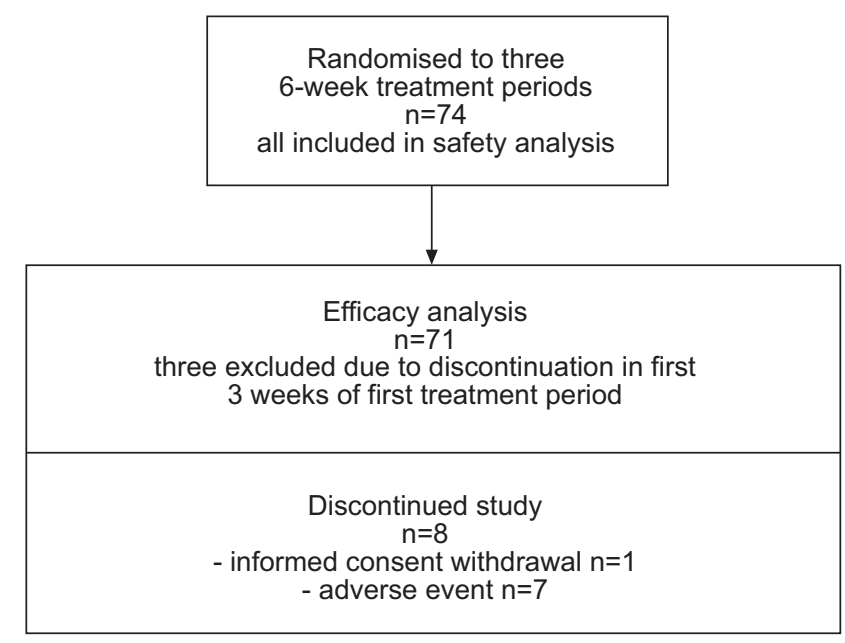

FIGURE 1. Flow diagram of the three-centre, randomised, double-blind (double-dummy), crossover study with three 6-week treatment periods. The diagram presents information on the number of patients who were randomised to treatment, included in the efficacy analysis and the number discontinued in the study.

\begin{tabular}{|c|c|c|}
\hline TABLE 2 & \multicolumn{2}{|c|}{$\begin{array}{l}\text { Demographics and characteristics of the study } \\
\text { population }\end{array}$} \\
\hline \multicolumn{3}{|l|}{ Variable } \\
\hline Subjects n & & $71^{\#}$ \\
\hline Males/femal & & $56 / 15$ \\
\hline Age yrs & & $64.9 \pm 9.4$ \\
\hline Smoking his & ry pack-yrs & $37.7 \pm 20.3$ \\
\hline Duration of & sease yrs & $10.9 \pm 7.2$ \\
\hline FEV 1 L & & $1.04 \pm 0.29$ \\
\hline FEV $1 \%$ prec & & $37.2 \pm 8.6$ \\
\hline FVC L & & $2.79 \pm 0.68$ \\
\hline FEV $_{1} /$ FVC $\%$ & & $37.9 \pm 7.9$ \\
\hline \multicolumn{3}{|c|}{ FEV1 reversibility } \\
\hline L & & $0.18 \pm 0.15$ \\
\hline$\%$ baseline & & $18.0 \pm 15.3$ \\
\hline$\%$ pred & & $6.4 \pm 5.3$ \\
\hline \multicolumn{3}{|c|}{ COPD severity ${ }^{+}$} \\
\hline Moderate & & $20(28)$ \\
\hline Severe & & $44(62)$ \\
\hline Very severe & & $7(10)$ \\
\hline \multicolumn{3}{|c|}{ Respiratory medication use } \\
\hline Any pulmo & ary medication & $71(100.0)$ \\
\hline Inhaled ant & holinergics & $59(83.1)$ \\
\hline Inhaled $\beta$-a & renergics & $68(95.8)$ \\
\hline Inhaled ste & & $63(88.7)$ \\
\hline Oral steroic & & $2(2.8)$ \\
\hline
\end{tabular}

Data are presented as $n$, mean $\pm S D$ and $n(\%)$. FEV 1 : forced expiratory volume in one second; FVC: forced vital capacity; COPD: chronic obstructive pulmonary disease. \#: patients included in efficacy analysis; ": response to 4 puffs of salbutamol $100 \mu \mathrm{g}$ (Ventolin $\mathbb{B}$ metered dose inhaler; GlaxoSmithKline B.V., Zeist, the Netherlands; and GlaxoSmithKline s.a./n.v., Genval, Belgium); +: according to Global Initiative for Chronic Obstructive Lung Disease (GOLD) criteria [1]

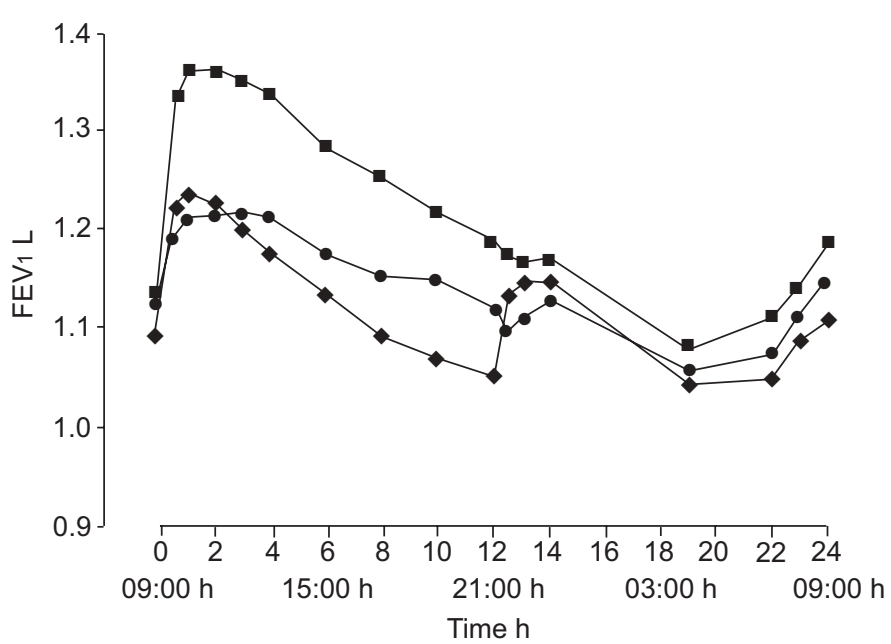

FIGURE 2. Mean forced expiratory volume in one second (FEV1; adjusted for period, centre and patient within centre) before and during $24 \mathrm{~h}$ after the inhalation of tiotropium q.d. (•), formoterol b.i.d. ( $)$, and tiotropium plus formoterol q.d. ( at the end of the 6-week treatment periods.

dose, no significant differences were observed between tiotropium and formoterol during the night-time, except, at the 24-h measurement (trough value), tiotropium was again superior to formoterol by $0.042 \mathrm{~L}(\mathrm{p}<0.05)$. The mean average, peak and trough responses for the single drugs, as well as the combination regimen, derived from the 24-h FEV1 timeresponse profiles are shown in table 3.

Compared with the individual components, the once-daily tiotropium plus formoterol treatment performed significantly better during the first $12-\mathrm{h}$ period after inhalation of the morning dose. The additional improvement in FEV1 versus tiotropium ranged from $0.070 \mathrm{~L}(p=0.001)$ to $0.151 \mathrm{~L}$ $(p<0.0001)$, whereas improvements compared with formoterol b.i.d. ranged $0.110-0.164 \mathrm{~L}(\mathrm{p}<0.0001)$. During the night-time (12-24 h), the combination regimen provided a significantly greater bronchodilation of $0.053 \mathrm{~L}(\mathrm{p}<0.01)$ compared with formoterol $7 \mathrm{~h}$ after the evening dose (i.e. $19 \mathrm{~h}$ after the morning dose of the combination at $\sim 04: 00 \mathrm{~h}$ ), which gradually increased to $0.079 \mathrm{~L}(\mathrm{p}<0.001)$ at the end of the 24 $\mathrm{h}$ observation period. The significant difference versus tiotropium observed during the daytime was sustained until $13 \mathrm{~h}$ after the morning dose $(0.060 \mathrm{~L} ; \mathrm{p}<0.02)$. During the nighttime, the combination regimen remained numerically superior until the end of the observation period.

The mean \pm SE baseline FVC at the start of the treatment periods was $2.631 \pm 0.08 \mathrm{~L}$. The pre-dose values after the 6week treatment period with tiotropium, formoterol or tiotropium plus formoterol were $2.793 \pm 0.03 \mathrm{~L}, 2.671 \pm 0.03 \mathrm{~L}$ or $2.790 \pm 0.03 \mathrm{~L}$, respectively; the difference between the combination regimen and formoterol, as well as that between tiotropium and formoterol, was significant $(p<0.002)$. The 24-h FVC profiles are depicted in figure 3, and the mean average, peak and trough responses for the three treatments derived from the FVC time-response curves are shown in table 3. The results for FVC closely reflected those obtained for FEV1. During the daytime, tiotropium provided a substantially longer duration of bronchodilation, as reflected by significant 


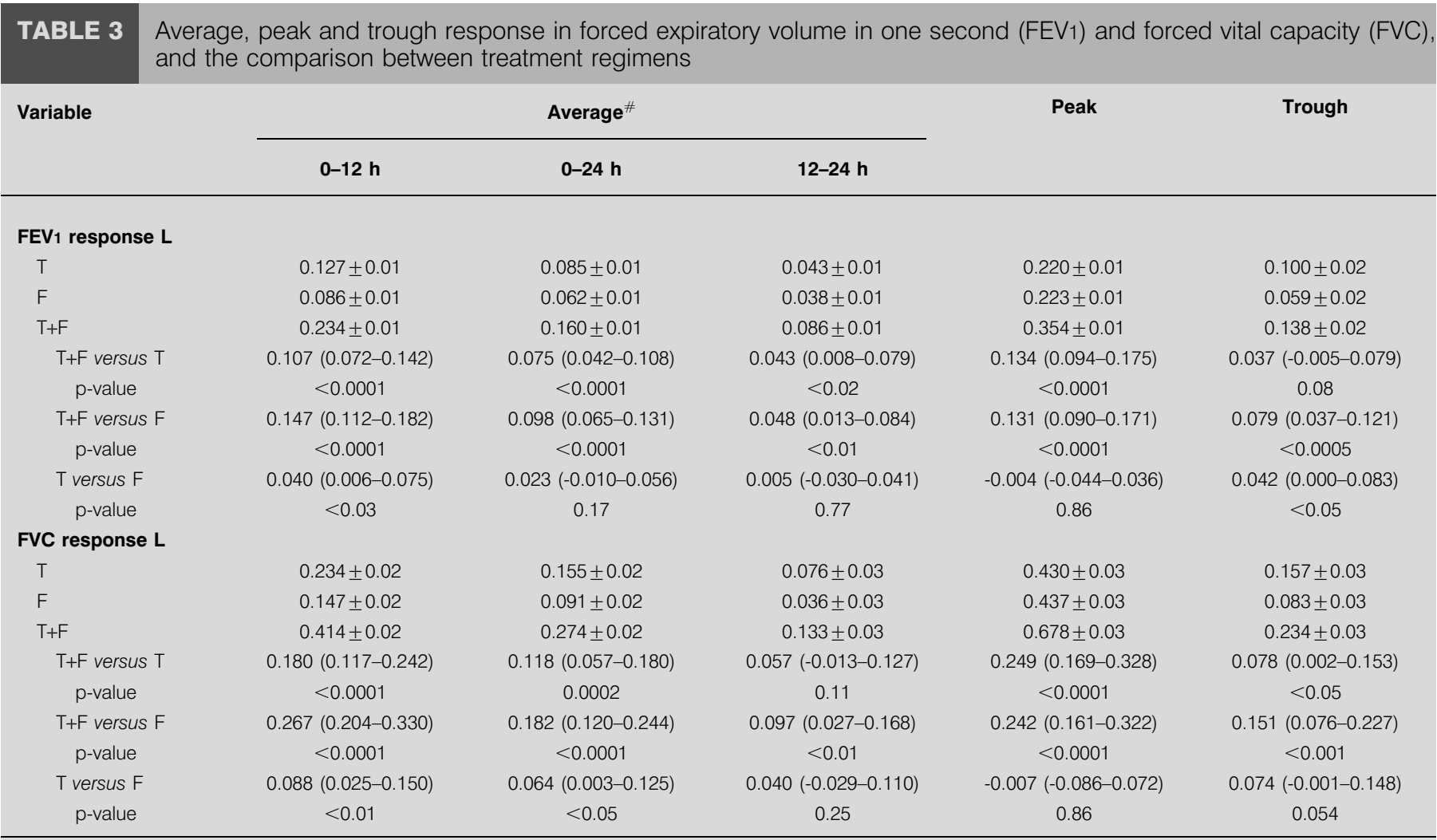

Data are presented as mean \pm SE and mean (95\% confidence interval), unless otherwise stated. Means are adjusted for period, centre and patient within centre. T: tiotropium q.d.; F: formoterol b.i.d.; T+F: tiotropium plus formoterol q.d.\#: the average was calculated as the area under the curve from zero time to 12 or $24 \mathrm{~h}$ (or $12-$ $24 \mathrm{~h}$ ), respectively, using the trapezoidal rule divided by the corresponding duration (i.e. 12 or $24 \mathrm{~h}$ ) to give the result in litres.

differences compared with formoterol, from $6 \mathrm{~h}$ following the morning dose until the end of the first 12-h dosing interval; the differences ranged from $0.116 \mathrm{~L}(\mathrm{p}<0.005)$ to $0.183 \mathrm{~L}$ $(\mathrm{p}<0.0001)$. During the second 12-h dosing interval (night-

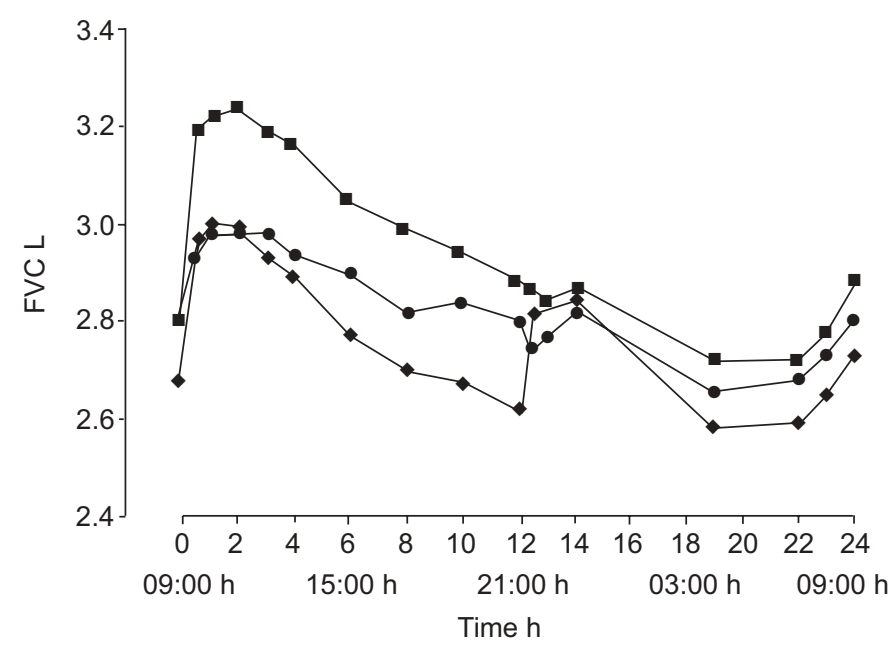

FIGURE 3. Mean forced vital capacity (FVC; adjusted for period, centre and patient within centre) before and during $24 \mathrm{~h}$ after inhalation of tiotropium q.d. (0), formoterol b.i.d. ( ), and tiotropium plus formoterol q.d. ( $\mathbf{\square})$ at the end of the 6week treatment periods. time), differences in favour of tiotropium were observed from $7 \mathrm{~h}$ post-evening dosing until the end of the observation period, i.e. on the next morning, which ranged from $0.070 \mathrm{~L}$ $(\mathrm{p}=0.075)$ at $19 \mathrm{~h}$ to $0.087 \mathrm{~L}(\mathrm{p}<0.05)$ at $22 \mathrm{~h}$.

The combination regimen was superior to the individual components during the first $12 \mathrm{~h}$ of the 24 -h period; the largest difference versus tiotropium was obtained $30 \mathrm{~min}$ after the morning dose $(0.278 \mathrm{~L} ; \mathrm{p}<0.0001)$ and versus formoterol at $8 \mathrm{~h}$ post-dosing $(0.292 \mathrm{~L} ; \mathrm{p}<0.0001)$. Throughout the night-time period, combination therapy provided a greater improvement in FVC compared with single-agent therapy. The difference between the combination and formoterol reached statistical significance from $7 \mathrm{~h}$ following the evening dose $(\sim 04: 00 \mathrm{~h})$, until the end of the second 12-h time interval (range 0.125$0.151 \mathrm{~L})$.

\section{PEFR and as-needed salbutamol use}

Morning and evening PEFR data are presented in table 4 . With respect to morning PEFR, the combination regimen was superior to formoterol by a statistically significant difference of $9.2 \mathrm{~L} \cdot \mathrm{min}^{-1}(\mathrm{p}<0.02)$. In line with the clinic spirometry results, a statistically significant higher evening PEFR was achieved with the combination compared to tiotropium $\left(9.8 \mathrm{~L} \cdot \mathrm{min}^{-1} ; \mathrm{p}<0.01\right)$, as well as formoterol $\left(17.1 \mathrm{~L} \cdot \mathrm{min}^{-1}\right.$; $\mathrm{p}<0.0001)$. Tiotropium was numerically superior to formoterol in both morning $\left(2.8 \mathrm{~L} \cdot \mathrm{min}^{-1}\right)$ and evening PEFR $\left(7.3 \mathrm{~L} \cdot \mathrm{min}^{-1}\right)$. 


\begin{tabular}{|c|c|c|c|}
\hline \multirow[t]{2}{*}{ TABLE 4} & \multicolumn{3}{|c|}{$\begin{array}{l}\text { Three-weekly morning/evening peak flow and } \\
\text { number of puffs per day of salbutamol }\end{array}$} \\
\hline & Tiotropium & Formoterol & Tiotropium and formoterol \\
\hline \multicolumn{4}{|c|}{ Peak flow L'min ${ }^{-1}$} \\
\hline Morning & $262 \pm 2.6$ & $259 \pm 2.6$ & $268 \pm 2.5^{\#}$ \\
\hline Evening & $274 \pm 2.8$ & $266 \pm 2.8$ & $283 \pm 2.6^{\bullet}$ \\
\hline \multicolumn{4}{|c|}{ Salbutamol p.r.n. } \\
\hline Daytime & $2.41 \pm 0.14$ & $2.37 \pm 0.14$ & $1.81 \pm 0.13^{+}$ \\
\hline Night-time & $0.56 \pm 0.05$ & $0.52 \pm 0.05$ & $0.52 \pm 0.05$ \\
\hline
\end{tabular}

Data are presented as mean \pm SE. $\#: p<0.02$ versus formoterol; $": p<0.01$ versus tiotropium and $p<0.0001$ versus formoterol; ${ }^{+}: p<0.003$ versus tiotropium plus formoterol. Means are adjusted for period, centre and patient within centre

Use of daytime rescue salbutamol was significantly reduced during treatment with the combination regimen $(\mathrm{p}<0.01$; table 4); no difference was found between the single drugs. Use of reliever medication was generally less during the nighttime, and no differences were found between the three treatment periods.

\section{Safety}

Seven patients discontinued the study prematurely due to an adverse event: one patient when on tiotropium (due to impaired balance), one patient during the formoterol period (due to a COPD exacerbation), and five during treatment with the combination (two patients due to a COPD exacerbation, two due to angina pectoris and one patient due to lung cancer). The events leading to discontinuation were classified as not related to the study drug.

No relevant differences were seen in the incidence of adverse events between the three treatment periods (table 5). Furthermore, measurements of blood pressure and pulse rate did not reveal any difference between the combination and the single drug periods. The post-study ECG recordings and laboratory safety screen (blood chemistry, haematology and urine analysis) did not indicate any study drug-induced changes from the baseline measurements.

\section{TABLE 5 Adverse events $\#$}

\begin{tabular}{|c|c|c|c|}
\hline Event & Tiotropium & Formoterol & $\begin{array}{l}\text { Tiotropium plus } \\
\text { formoterol }\end{array}$ \\
\hline Total treated $\mathbf{n}$ & 70 & 69 & 71 \\
\hline $\begin{array}{l}\text { Total with any adverse } \\
\text { events }\end{array}$ & $29(41.4)$ & $32(46.4)$ & $27(38.0)$ \\
\hline Nasopharyngitis & $9(12.9)$ & $4(5.8)$ & $4(5.6)$ \\
\hline Headache & $4(5.7)$ & $1(1.4)$ & $0(0.0)$ \\
\hline Exacerbation of COPD & $4(5.7)$ & $14(20.3)$ & $10(14.1)$ \\
\hline Dyspnoea exacerbated & $7(10.0)$ & $12(17.4)$ & $4(5.6)$ \\
\hline
\end{tabular}

Data are presented as $n(\%)$, unless otherwise stated. COPD: chronic obstructive pulmonary disease. ${ }^{*}$ : occurring in $\geqslant 3 \%$ of the patients.

\section{DISCUSSION}

The present study is the first to report the combined bronchodilator effects of tiotropium and formoterol in COPD, both drugs once daily, compared with the effects of the individual components tiotropium q.d. and formoterol b.i.d., following treatment periods of 6 weeks and including serial spirometric assessments over a 24 -h period. The single agents tiotropium and formoterol provided significant improvements in pulmonary function (FEV1 and FVC), with tiotropium being superior to formoterol during the daytime $(0-12 \mathrm{~h})$. The most pronounced bronchodilator effects, however, were achieved with the once-daily combination treatment. In terms of the average response during the daytime $(0-12 \mathrm{~h})$, as well as during the night-time (12-24 h), the combination regimen was superior to single-agent therapy.

As long-acting bronchodilators are the recommended regular treatments in the management of moderate-to-severe COPD [1, 2], and, as several options exist for mono- or combination therapy with these agents, it is essential to provide healthcare providers with comparative clinical data. Although comparable improvements in peak FEV1 and FVC were achieved following the morning dose of the individual treatment regimens, tiotropium was superior $(p<0.05)$ to formoterol in terms of the average FEV1 and FVC (0-12 h). This was due to a substantially longer duration of action of tiotropium. During the second 12-h dosing interval of formoterol, i.e. the nighttime period (12-24 h), no significant differences were found between the single drugs. The next morning, i.e. $24 \mathrm{~h}$ after the last tiotropium dose and $12 \mathrm{~h}$ after the last formoterol dose, higher trough FEV1 and FVC values were observed for tiotropium.

In the present COPD population, the most favourable bronchodilation was achieved with the combination treatment. Significantly higher peak and average FEV1 and FVC responses were observed as compared with either component in its recommended posology alone. Particularly, during the relevant period of daily activities $(0-12 \mathrm{~h})$, the combination regimen appeared to provide additive bronchodilator effects. The value of a once-daily combination as a therapeutic option is further strengthened by the additive effect during the night-time period of the 24-h dosing interval, as reflected in the superior average FEV1 (12-24 h) response over the components $(p<0.02)$ and the trend for a higher trough FEV1 24-h post-dosing value of the combination compared with formoterol b.i.d. $(+0.08 \mathrm{~L} ; \mathrm{p}=0.0003)$ or tiotropium q.d. $(+0.04 \mathrm{~L} ; \mathrm{p}=0.081)$. These findings differ substantially from the results of the recently published acute dosing study of tiotropium, formoterol and its combination over $24 \mathrm{~h}$ by CAzzola et al. [13]. In this study, no statistically significant differences were observed between a single dose of the combination regimen and a single dose of either of the two individual drugs. However, any comparison between the studies is hampered by the fact that, as indicated by CAzzola et al. [13], their study appeared to be underpowered, and spirometric measurements were not performed in pharmacodynamic steady state and, in addition, were missing during the night-time. As shown previously, optimal bronchodilatory responses by tiotropium are achieved in pharmacodynamic steady state [22], meaning that definitive conclusions on the pulmonary effects of the single drugs in 
relation to their combination can only be drawn following maintenance therapy. Furthermore, bronchodilator-induced modifications of the circadian variation in airflow limitation can only be established when the study design includes measurements during the night and the early morning hours when the FEV1 values are lowest [23]. Finally, in the current study, it is unlikely that the bronchodilating activity of formoterol was diminished, since long-term studies have shown no tolerance to the bronchodilation effect of formoterol in COPD [24, 25].

Comparing the time course of the FEV1 and FVC profiles of the combination regimen with the single agents, it appears that the morning dose of formoterol, in addition to tiotropium, can still provide added efficacy after $12 \mathrm{~h}$ (end of dosing interval), whereas formoterol alone had returned to the test-day (morning) baseline. In addition, the average night-time FEV1 (12-24 h) differed significantly from monotherapy with tiotropium. These findings suggest a more than additive effect, i.e. the combined effect is higher or longer acting than predicted from addition of the components.

Serial spirometry was not recorded following the first dose as the acute first-dose effect was not considered relevant for a chronic maintenance therapy, and particularly so for tiotropium, which requires several doses to reach pharmacodynamic steady state [22]. Furthermore, the effect of the combination was tested once daily for both formoterol and tiotropium, although the most commonly used posology for formoterol is twice daily. As COPD is characterised by dyspnoea on exertion mainly during the daytime waking hours, it was hypothesised that the convenient once-daily combination would provide optimal bronchodilation during this relevant period of the day, whereas the sustained 24-h bronchodilator activity of the tiotropium component would provide sufficient bronchodilation during the night-time. This is consistent with the findings by POsTMA et al. [23], who demonstrated that the activity of the adrenergic system is most prominent during the day, whereas an increased parasympathetic system activity was found during the night. The hypothesis would be further validated by comparing the need for short-acting bronchodilator rescue medication during the daytime and night-time as a surrogate parameter for additional need for relief from dyspnoea. In this respect, it is interesting to note that previous studies in COPD have also shown less salbutamol consumption during the night-time [26, 27]. In terms of reliever medication, the present data are in agreement with the current authors' previous study on the combination therapy of tiotropium and formoterol [14].

Regular treatment with inhaled glucocorticosteroids is indicated for symptomatic COPD patients with a postbronchodilator FEV1 $<50 \%$ pred and repeated exacerbations [1]. In order to be eligible for the present study, patients needed to have a pre-bronchodilator FEV1 $\leqslant 60 \%$ pred. Therefore, it is not surprising that a large proportion of the study population used inhaled glucocorticosteroids concomitantly. Recent studies have demonstrated that the combination of a LABA with an inhaled glucocorticosteroid is more effective than the individual components in improving and maintaining lung function during long-term therapy [28-31].
As controlled prospective clinical data on a combination of tiotropium and an inhaled glucocorticosteroid is not available, the potential additive effect of the inhaled glucocorticosteroids on the lung function improvements found for tiotropium and the combination regimen can only be speculated about. The type and doses of the inhaled glucocorticosteroids varied and were not standardised within the present population. Despite $89 \%$ of the patients receiving inhaled glucocorticosteroids, tiotropium provided a greater improvement in daytime lung function and equal improvement in night-time lung function compared with formoterol. In addition, a significant additive bronchodilator effect was achieved with the combination of the two different classes of longacting bronchodilators, in addition to concomitantly inhaled glucocorticosteroids.

Bronchodilator therapy in COPD may be considered successful if relief from dyspnoea is provided, which should translate into a decrease in the need for an additional bronchodilator. Reduction in rescue need with short-acting $\beta$-agonists has been previously demonstrated in patients receiving longacting bronchodilators [8, 9, 24, 32-34]. In the current study, significantly less as-needed use of salbutamol reflects the bronchodilator-mediated symptomatic benefit of the combination regimen over the single drugs. The reduction in 24-h rescue medication use was due to a reduction during the daytime, the time when patients tend to be active. This finding suggests that optimal bronchodilation during the waking hours could improve the patients' limitations in daytime physical activity. To what extent less use of reliever medication is translated into clinical benefit, such as an improvement in, for instance, exercise performance, remains to be established. Eventually, the goals of treatment in COPD target beyond the optimisation of lung function. The full clinical potential of a combination of tiotropium and a long-acting $\beta$-adrenergic over the individual components, in terms of reducing dyspnoea, prevention of COPD exacerbations and the improvement of quality of life, can only be evaluated in larger-scale long-term studies. In particular, these studies have eventually to resolve the question on the therapeutic value of a once-daily combination relative to a combination with twice-daily LABA dosing.

In summary, the current authors have found that once-daily tiotropium provides superior bronchodilation during the daytime as compared with twice-daily formoterol in patients with moderate-to-severe chronic obstructive pulmonary disease; during the night-time, no difference was observed between the two long-acting bronchodilator treatment regimes. A combination of both drugs exhibited additive effects in terms of daytime lung function improvements and sustained improvements during the night compared with the single components, despite the once-daily dosing. As recommended by the Global Initiative for Chronic Obstructive Lung Disease guidelines [1], a combination of two long-acting bronchodilators with different pharmacological mechanisms of action should be considered in all patients with moderateto-severe chronic obstructive pulmonary disease. In this respect, the present clinical study is the first to support this recommendation for the treatment of moderate-to-severe chronic obstructive pulmonary disease. 


\section{REFERENCES}

1 Global Initiative for Chronic Obstructive Lung Disease. Global Strategy for the Diagnosis, Management and Prevention of Chronic Obstructive Pulmonary Disease. NHLBI/WHO workshop report. Bethesda, National Heart, Lung and Blood Institute, 2001. Update of the management sections. www.goldcopd.com. Date last updated: May 21 2004. Date last accessed: May 272005.

2 Celli BR, MacNee W. ATS/ERS Task Force, Standards for the diagnosis and treatment of patients with COPD: a summary of the ATS/ERS position paper. Eur Respir J 2004; 23: 932-946.

3 Jarvis B, Markham A. Inhaled salmeterol: a review of its efficacy in chronic obstructive pulmonary disease. Drugs Aging 2001; 18: 441-472.

4 Friedman M, Della Cioppa G, Kottakis J. Formoterol therapy for chronic obstructive pulmonary disease: a review of the literature. Pharmacotherapy 2002; 22: 1129-1139.

5 Cazzola M, Donner CF. Long-acting $\beta_{2}$ agonists in the management of stable chronic obstructive pulmonary disease. Drugs 2000; 60: 307-320.

6 Rees PJ. Tiotropium in the management of chronic obstructive pulmonary disease. Eur Respir J 2002; 19: 205-206.

7 Hansel TT, Barnes PJ. Tiotropium bromide: a novel oncedaily anticholinergic bronchodilator for the treatment of COPD. Drugs Today (Barc) 2002; 38: 585-600.

8 Casaburi R, Mahler DA, Jones PW, et al. A long-term evaluation of once-daily inhaled tiotropium in chronic obstructive pulmonary disease. Eur Respir J 2002; 19: 217-224.

9 Vincken W, van Noord JA, Greefhorst APM, et al. Improved health outcomes in patients with COPD during 1 yr's treatment with tiotropium. Eur Respir J 2002; 19: 209-216.

10 Donohue JF, van Noord JA, Bateman ED, et al. A 6-month, placebo-controlled study comparing lung function and health status changes in COPD patients treated with tiotropium and salmeterol. Chest 2002; 122: 47-55.

11 Brusasco V, Hodder R, Miravitlles M, Korducki L, Towse L, Kesten S. Health outcomes following treatment for six months with once daily tiotropium compared with twice daily salmeterol in patients with COPD. Thorax 2003; 58: 399-404.

12 Tennant RC, Erin EM, Barnes PJ, Hansel TT. Long-acting $\beta_{2}$-adrenoceptor agonists or tiotropium bromide for patients with COPD: is combination therapy justified? Curr Opin Pharmacol 2003; 3: 270-278.

13 Cazzola M, Di Marco F, Santus P, et al. The pharmacodynamic effects of single inhaled doses of formoterol, tiotropium and their combination in patients with COPD. Pulm Pharmacol Ther 2004; 17: 35-39.

14 van Noord JA, Aumann J, Janssens E, Folgering $\mathrm{H}$, Mueller A, Cornelissen PJG. Tiotropium maintenance therapy in patients with COPD and the 24-h spirometric benefit of adding once or twice daily formoterol during 2week treatment periods. Am J Respir Crit Care Med 2003; 167: Suppl. 7, A95.

15 American Thoracic Society. Standards for the diagnosis and care of patients with chronic obstructive pulmonary disease. Am J Respir Crit Care Med 1995; 152: S77-S120.
16 Quanjer PH, Tammeling GJ, Cotes JE, Pederson OF, Peslin R, Yernault J-C. Lung volumes and forced ventilatory flow. Eur Respir J 1993; 6: Suppl. 16, 5-40.

17 American Thoracic Society. Standardization of spirometry - 1994 update. Am J Respir Crit Care Med 1995; 152: 1107-1136.

18 Calverley PMA, Lee A, Towse L, van Noord JA, Witek TJ, Kesten S. Effect of tiotropium on circadian variation in airflow limitation in chronic obstructive pulmonary disease. Thorax 2003; 58: 855-860.

19 Maesen FPV, Smeets JJ, Sledsens TJH, Wald FDM, Cornelissen PJG. Tiotropium bromide, a new long-acting antimuscarinic bronchodilator: a pharmacodynamic study in patients with chronic obstructive pulmonary disease (COPD). Dutch Study Group. Eur Respir J 1995; 8: 1506-1513.

20 Yates DH, Sussman HS, Shaw MJ, Barnes PJ, Chung KF. Regular formoterol treatment in mild asthma. Effect on bronchial responsiveness during and after treatment. Am J Respir Crit Care Med 1995; 152: 1170-1174.

21 Littner MR, Ilowite JS, Tashkin DP, et al. Long-acting bronchodilation with once-daily dosing of tiotropium (Spiriva) in stable chronic obstructive pulmonary disease. Am J Respir Crit Care Med 2000; 161: 1136-1142.

22 van Noord JA, Smeets JJ, Custers FLJ, Korducki L, Cornelissen PJG. Pharmacodynamic steady state of tiotropium in patients with chronic obstructive pulmonary disease. Eur Respir J 2002; 19: 639-644.

23 Postma DS, Keyzer JJ, Koëter GH, Sluiter HJ, De Vries K. Influence of the parasympathetic and sympathetic nervous system on nocturnal bronchial obstruction. Clin Sci (Lond) 1985; 69: 251-258.

24 Dahl R, Greefhorst APM, Nowak D, et al. Inhaled formoterol dry powder versus ipratropium bromide in chronic obstructive pulmonary disease. Am J Respir Crit Care Med 2001; 164: 778-784.

25 Aalbers R, Ayres J, Backer V, et al. Formoterol in patients with chronic obstructive pulmonary disease: a randomized, controlled, 3-month trial. Eur Respir J 2002; 19: 936-943.

26 Ulrik CS. Efficacy of inhaled salmeterol in the management of smokers with chronic obstructive pulmonary disease: a single centre randomized, double-blind, placebocontrolled, crossover study. Thorax 1995; 590: 750-754.

27 Donohue JF, Kotch A, Menjoge SS, Witek TJ, Kesten S. Circadian patterns of rescue $\beta_{2}$-agonist use in COPD. Eur Respir J 2000; 16: Suppl. 31, 56s.

28 Szafranski W, Cukier A, Ramirez A, et al. Efficacy and safety of budesonide/formoterol in the management of chronic obstructive pulmonary disease. Eur Respir J 2003; 21: 74-81.

29 Calverley PM, Boonsawat W, Cseke Z, Zhong N, Peterson S, Olsson H. Maintenance therapy with budesonide and formoterol in chronic obstructive pulmonary disease. Eur Respir J 2003; 22: 912-919.

30 Mahler DA, Wire P, Horstman D, et al. Effectiveness of fluticasone propionate and salmeterol combination delivered via the Diskus device in the treatment of chronic obstructive pulmonary disease. Am J Respir Crit Care Med 2002; 166: 1084-1091. 
31 Calverley P, Pauwels R, Vestbo J, et al. Combined salmeterol and fluticasone in the treatment of chronic obstructive pulmonary disease: a randomized controlled trial. Lancet 2003; 361: 449-456.

32 Jones PW, Bosh TK. Quality of life changes in COPD patients treated with salmeterol. Am J Respir Crit Care Med 1997; 155: 1283-1289.
33 Mahler DA, Donohue JF, Barbee RA, et al. Efficacy of salmeterol xinofoate in the treatment of COPD. Chest 1999; 115: 957-965.

34 Rennard SI, Anderson W, ZuWallack R, et al. Use of a longacting inhaled $\beta_{2}$-adrenergic agonist, salmeterol xinafoate, in patients with chronic obstructive pulmonary disease. Am J Respir Crit Care Med 2001; 163: 1087-1092. 